\title{
Improving the Drilling Process by Its Adaptive Control
}

Karol Vasilko

Faculty of Manufacturing Technology, Technical University of Košice, 08001 rešov, Bayerova 1, SR, M: karol.vasilko@tuke.sk

The experience from the use of NC tool machines has shown that it is not enough to optimise cutting conditions, without more detailed knowledge of machining process [1], [7]. Numereical control of a tool machine enables new possibilities to oprimise machining and provide more space to the technologist to deal with technological process in a creative way. This process is suggested on an example of a simple helical drill. Similar approach cenbe adapted for milling when the cut width increases gradually, when turning threads, teething and other frequent machining operations.

Keywords: machining, cutting time, cutting force, tool life, drilling, durability

\section{Indroduction}

Classical production machining methods are based on cutting conditions: $v_{\mathrm{c}}, a_{\mathrm{p}} ; f$. These are usually dept contact during the entire machining process of a centrain workpiece area [8], [12]. The change in cutting speed occurs e. g. when turning the face plate. The change in cutting speed occurs e. g. when turning the workpiece face at a constant spindle speed. The cutting depth varies when machining forgings and castings that have technological bevels [14]. The feed rate does not normally change during machining, as this ensures a constant ualiz of the machined surface. The stability of the cutting conditions determines the uality of the machined surface. The stability of the cutting conditions determines the machine time for which the general relation formula: $\tau=\frac{l}{n \cdot f}$, [7], [12], where 1 is the leght of the surface to be machinined; $n$ - the rotational freuency of the workpiece (or tool); $f$ - the feed rate per rotation of the workpiece (or tool) [6],[11].A deeper analysis of the machining process shows that a purposeful change in cutting conditions $(n, f)$ can positively affect the cutting process and its results [5], [14].

\section{Drilling process control}

With classical helical drills, according to Fig. 1, cutting speed and tool geometric parameters change along the cutting edge. Besides those changes, the existence of vertical cutting edge makes the drill incision more difficult, from its first contact with the workpiece up to reaching full contact along the whole length of cutting edges.

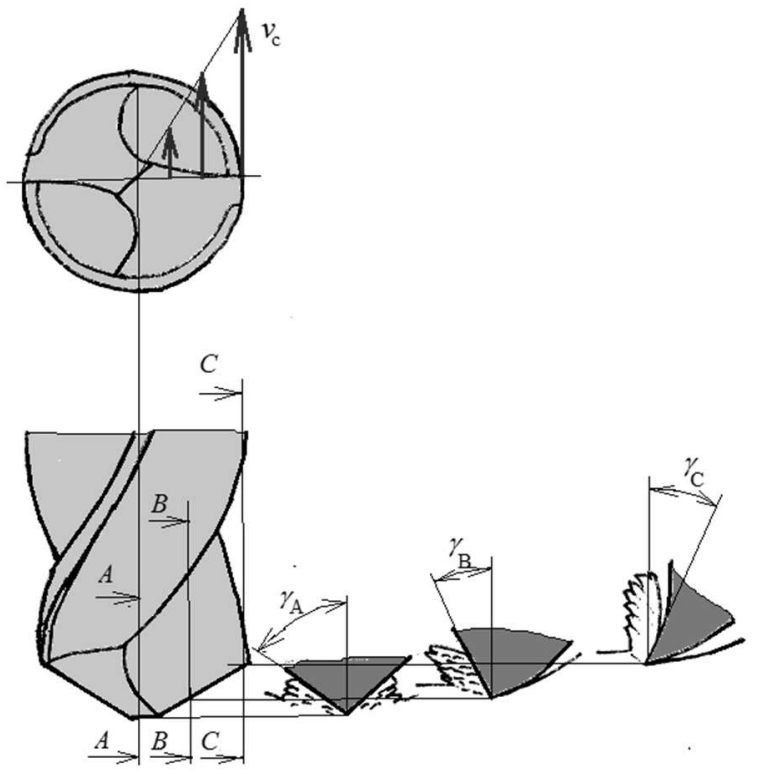

Fig. 1Change of drill geometric parameters when incising the workpiece

Face angle changes considerably, on which the process of chip formation depends. Similar unfavourable conditions occur when the drill leaves the hole and this often leads to priority drill wear.

In Fig. 2 there is the result of experiments aimed at measurement of axial cutting force when drilling steel and alloy with drills made of high-speed steel.

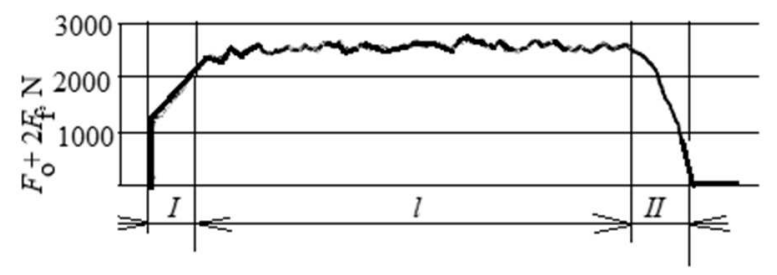

a) 


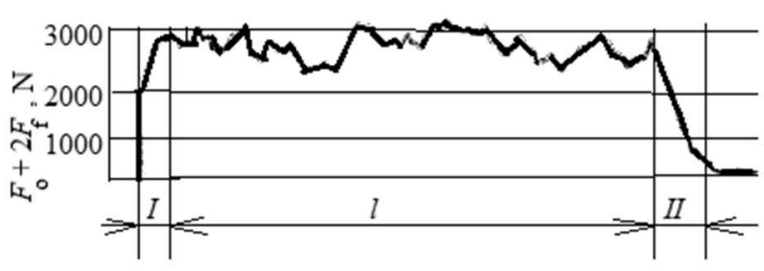

b)

Fig. 2 Change of axial forces when drilling holes in alloy (a) and steel (b) by drills made of high-speed steel HS12-1-2 diameter $12 \mathrm{~mm}$. Cutting conditions: $a: f=0.21 \mathrm{~mm}, v_{c}=$ $23.7 \mathrm{~m} . \mathrm{min}^{-1}, b: f=0.16 \mathrm{~mm}, v_{c}=23.7 \mathrm{~m} . \mathrm{min}^{-1}$

It can be seen that when the drill enters the feed, axial cutting force $\left(F_{\mathrm{o}}+2 F_{\mathrm{f}}\right)$ grows steeply. It is caused by the fact that only lateral cutting edge is in feed at the first contact. Face angle is negative, which means there is much higher rate of plastic deformation of cut material when it is transformed into the chip. The feed gradually spreads to both cutting edges, by which the forces $F_{\mathrm{f}}$ grow. The character of the increase of axial cutting force depends on the rigidity of technological system. The higher the rigidity, the steeper the increase of axial force. When drilling steel, the zone of fluent drilling becomes evident by observable fluctuation of the force, which is the effect of the chip formation characteristic for steel (fluent chip with slides, which affects whole chip cross section). Higher dynamics of cutting force is shown in drilling alloy because here occurs crack-formation process together with the formation of a segmented chip. Similarly, when the drill leaves the feed, the decrease of the cutting force is different for alloy and for steel. When drilling alloy, more fluent decrease has been recorded, which is probably the result of gradual release of a flexibly deformed system. For steel, this decrease is steeper.

Experimental tests have shown that the character of cutting force change when entering and leaving the feed can be influenced by the change of drill rotation frequency or the change of feed, which can be provided by the correction of NC machine control programme. Drill durability for standard cutting conditions and changing shift have been experimentally compared. The tests have been performed for drilling alloy with coated tools made of hight-speed steel HS12-1-2 with diameter $12 \mathrm{~mm}$ and lenght $40 \mathrm{~mm}$. Standard cutting conditions recommend to use feed $f=$ $0.21 \mathrm{~mm}$. In modified mode, the feeds, when the drill was entering and leaving, decreased by $40-50 \%$. At the same time, the feeds when drilling in the central part of the hole have been increased by $20-25 \%$. Corresponding feeds have been: $f_{1,3}=0.18 \mathrm{~mm}, f_{2}=0.25 \mathrm{~mm}$. This procedure can be reasoned by the fact that during standard drilling, the selected feed is a little smaller than the allowed one due to complex feed conditions when the drill enters.
In Fig. 3 there is a technological cycle of drilling in standard and modified modes.
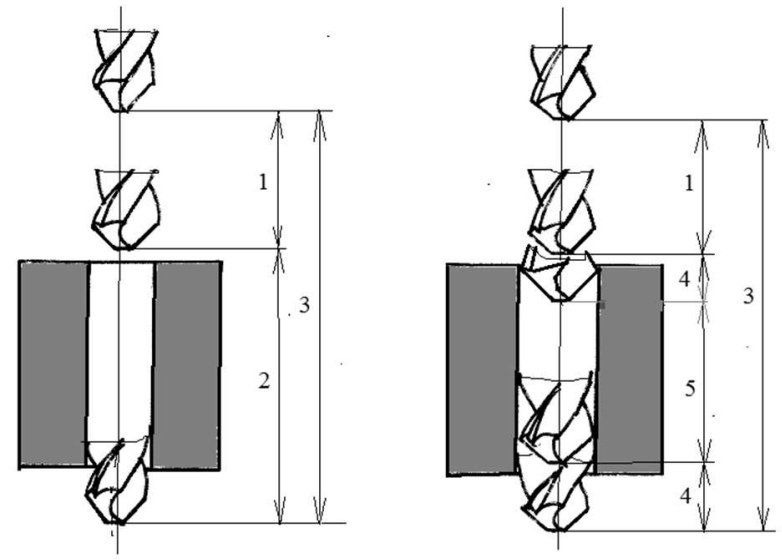

Fig. 3 Technological process of drilling. $a-$ standard, $b$ - modified. 1 - speed-feed, 2 - working feed, 3 - reverse speed-feed, 4 - decreased feed, 5 - increased feed

In Fig. 4 there is a comparison of average durability of drill series when machining in standard and modified conditions.

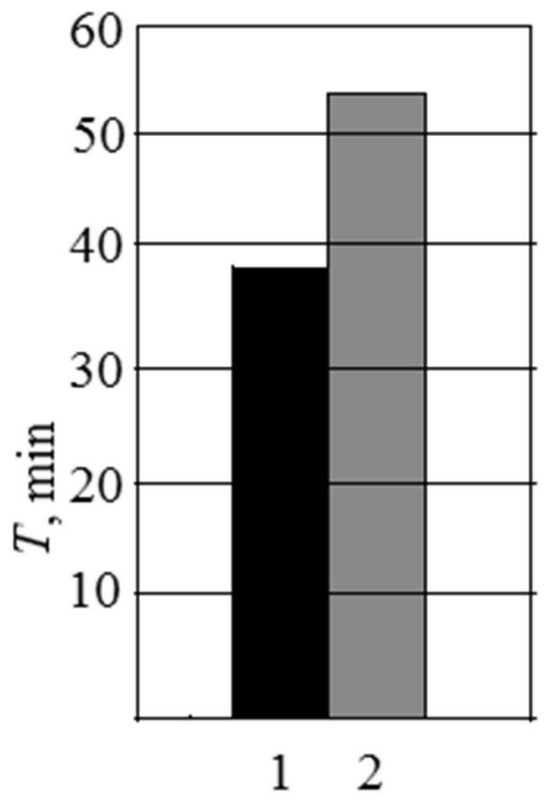

Fig. 4 Tool durability when drilling in standard conditions (1) and varying feed (2)

Significant increase of tool durability has been recorded when drilling holes with varying feed. At the same time, machining time has decreased by cca $10 \%$.

Following tests have been oriented towards the study of the influence of cutting speed on drill durability. The tests have been performed when drilling holes in box parts made of grey alloy with flowing coat on the leaving side of drills outward the feed. Standard helical drills with diameter $17.5 \mathrm{~mm}$ made of highspeed steels HS7-4-2-5 and HS12-1-2 and sintered 
carbud K10 have been used as tools. Holes $50 \mathrm{~mm}$ long have been machined. Different cutting speeds have been obtained by fluent change of spindle rotation frequency, for fluent drilling and leaving the feed; for standard machining, cutting speeds of normatívov $16.5 \mathrm{~m} \cdot \mathrm{min}^{-1}$ for drills made of high-speed steel and 26 m. min $^{-1}$ for drills made of sintered carbid have been selected from standards.

When the drill has been leaving the feed, the cutting speed has been decreased by $25 \%$, i.e. to $12.5 \mathrm{~m} . \mathrm{min}^{-1}$ for high-speed drills and $21 \mathrm{~m} \cdot \mathrm{min}^{-1}$ for drills made of sintered carbid. The feed has remained constant, $f=0.32$ and $0.28 \mathrm{~mm}$.

Technological process of drilling in both cases is shown in Fig. 5.
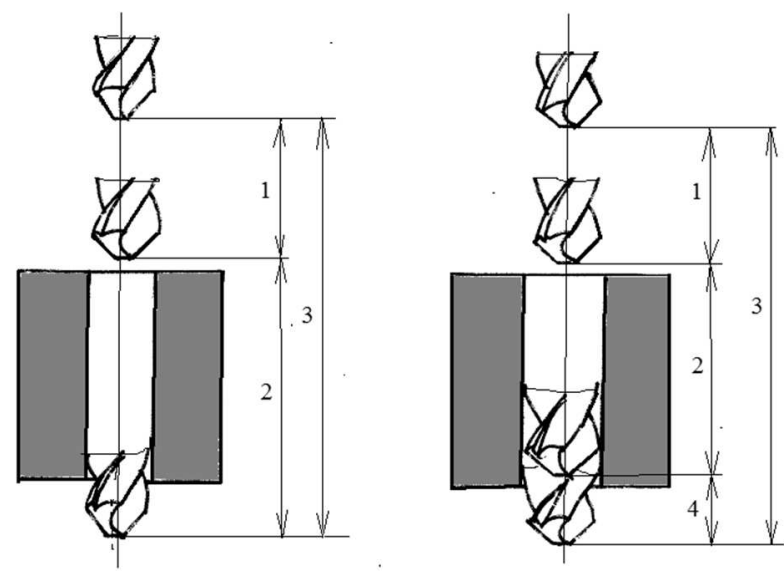

Fig. 5 Technological process of drilling, $a-$ standard, $b-$ modified. 1 - bigh-feed, 2 - standard feed, 3 - reverse highfeed, 4 - decreased feed

Following statistic processing, the results are presented in Fig. 6.

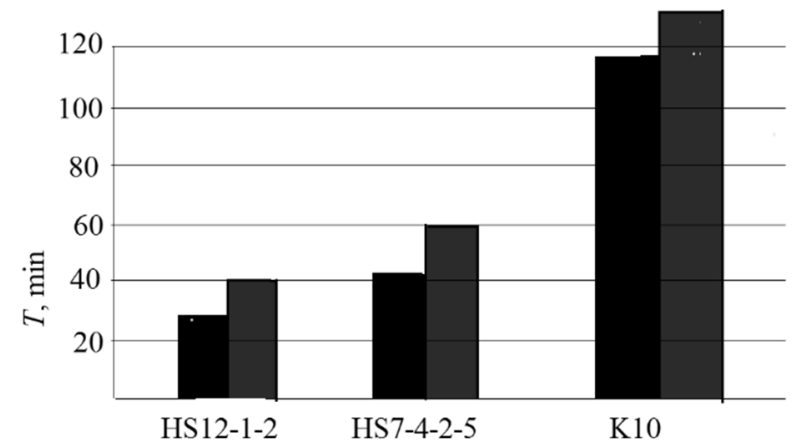

Fig. 6 Average drill durability when drilling with standard modes (black columns) and varying cutting speed

Another series of tests have been devoted to the conditions of fluent incision of drills into cut material. The zone of incision has been divided into several sections on which the cutting speed was changing. The tests have been performed with drills with diameter $12 \mathrm{~mm}$, with which the course of incision $4.8 \mathrm{~mm}$ corresponds. This section is divided into three parts,
$1.5 \mathrm{~mm}$ each. Based on the analysis of machining scheme, different cutting speed has been selected for each section.

When incising in the first section under the hindered conditions, when the lateral cutting edge deforms the material, the feed has changed twice and the spindle rotation frequency increased 4 times. Analogically, in the second section, the feed decreased by $20-25 \%$, with corresponding increase of spindle rotation frequency 1.5 times. In the third section, the conditions have satisfied the standard ones.

The results of measuring axial force are demonstrated in Fig. 7.

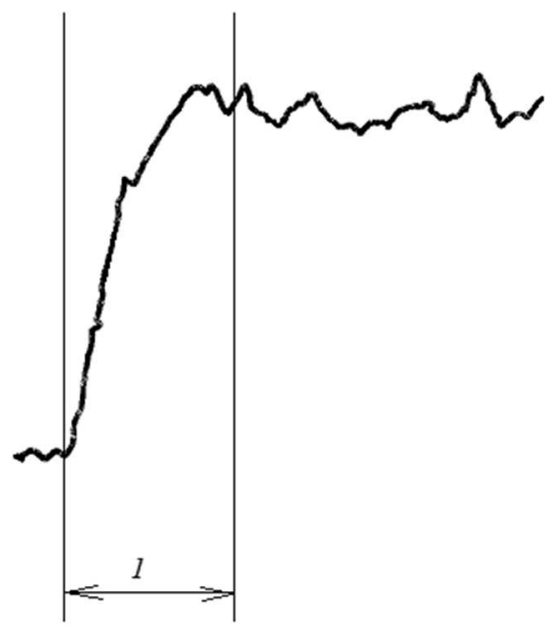

a)

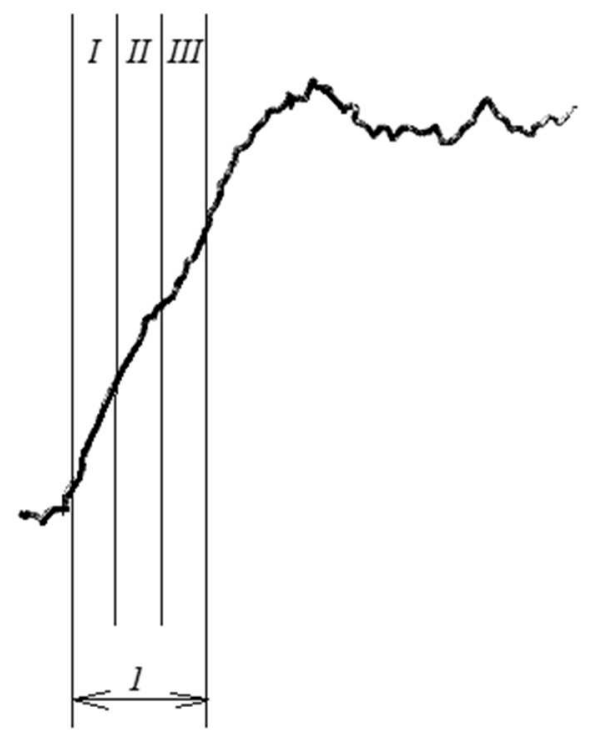

b)

Fig. 7 Character of change of axial force during incision of drills made of HS12-1-2 into a workpiece made of steel C45. a: at standard modes, $f=0.14 \mathrm{~mm}, n=800 \mathrm{~min}^{-1}\left(v_{c}=30\right.$ m.min $\left.{ }^{-1}\right)$. b: after dividing the zone of incision into 3 sections $I$ $: D_{1}=4 \mathrm{~mm}, n=2400 \mathrm{~min}^{-1}\left(v_{c}=30.1 \mathrm{~m}^{\mathrm{min}}{ }^{-1}\right) . I I: D=$ $8 \mathrm{~mm}, n=1200 \mathrm{mim}^{-1},\left(v_{c}=30 \mathrm{~m} \cdot \mathrm{min}^{-1}\right), \mathrm{III}: \mathrm{D}=12$ mm, $n=800$ min $^{-1}\left(v_{c}=30\right.$ m.min $\left.{ }^{-1}\right)$. 
It can be seen that with the change of spindle rotation frequency and shift, a more fluent course of cutting force can be obtained, at the same time shortening of machine time by $30-35 \%$ can be reached.

Fluent change of spindle rotation frequency presentes a more effective method to improve the conditions of incision. Recent $\mathrm{CNC}$ systems allow to vary the spindle rotation frequency and shift fluently, according to designated law, on an optional machining system. The results of the studies have proved that the change of feed and cutting speed at the drill entering and leaving the feed can considerably improve the character of transition processes in this area. Another positive result of experimental tests is the fact that besides improved conditions of drill operation on transition section, the probability of drill breaking also decreases.

\section{Optimation of cutting conditions when boring in the center of the hole}

In the previous chapter, the optimation of cutting conditions in transition conditions has been described. Next, the optimation of the drilling process in the section of stable machining will be dealt with.

The first part of the experiments has been performed only with regulated feed. The range of regulation, which is enabled by the system of adaptive control has been $20-120 \%$ with a step $10 \%$. It means that the standard feed is considered to be $100 \%$, in the course of regulation the feed can decrease by $80 \%$ and increase by $20 \%$.

In Fig. 8 there are the results of measurment of axial force when drilling the base part of the opening in standard drilling conditions and with the use of the system of adaptive control with different feeds.

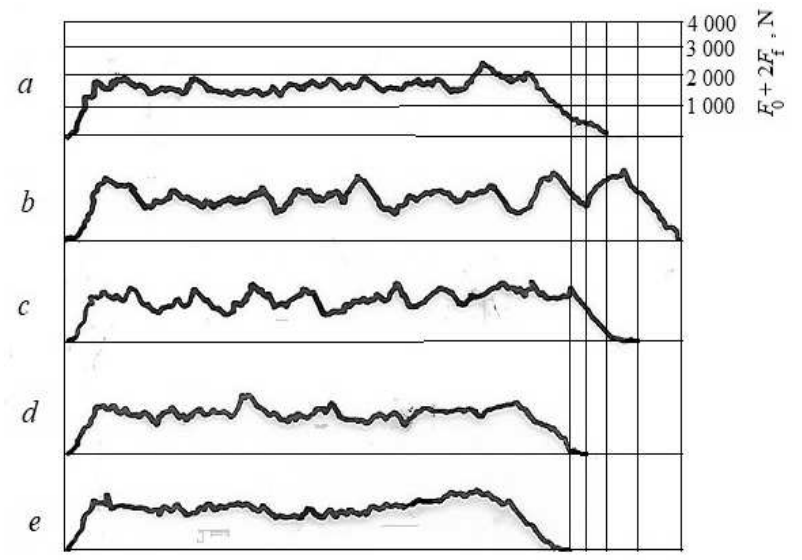

Fig. 8 Character of change of axial force in different range of regulated feed when drilling steel C45 with drills HS12-1-2, diameter $12 \mathrm{~mm} . v_{c}=30.1 \mathrm{~m} . \mathrm{min}^{-1}$, hole length: $40 \mathrm{~mm} . \mathrm{a}-$ at standard cutting conditions: $f_{m}=114 \mathrm{~mm} \cdot \mathrm{min}^{-1}, \mathrm{~N}=$ $0.7 \mathrm{~kW} . b-$ at the range of regulated feed $20-120 \%, s_{m}=$ $22-137$ mm. min ${ }^{-1}, c-40-120 \%\left(114-136\right.$ mm. min $\left.{ }^{-1}\right)$, $d-60-120 \%, e-80-120 \%$.
The courses $a$ and $b$ show that in comparison with standard mode, it is not possible to obtain smaller fluctuation of cutting force for the use of adaptive control with the range of regulation $20-120 \%$ and fixed performance $0.7 \mathrm{~kW}$. At the same time, machine time increases by $20 \%$. It can be explained by the fact that when drilling steel, a fluent chip is formed and after it breaks off, the axial force decreases. When drilling with adaptive control, the system reacts to the change of this force and at the regulation it evokes even higher force fluctuation as a result of intertia, mainly for a wide range of regulation. With the decreased range of regulation (Fig. $c, d, e$ ), the dynamic element of cutting force gradually decreases and in the range of regulation $100-120 \%$ it is much smaller compared to the operation without regulation. At the same time, machine time shortens by cca $10 \%$.

\section{Conclusion}

The application of adaptive control of machining process on $\mathrm{CNC}$ tool machines enables new possibilities to optimise the process. The result is the increase of tool durability and shortening of machine time. The programmer is required to master the machining process and know the importance of tool geometry and the influence of cutting conditions of the results of machining. An important effect can be seen on workpieces where there occurs a change of some geometric parameter, e.g. width of machined surface of the cross-cut section of cut-off layer within the course of machining.

\section{References}

[1] HOLOBOV, A, A., et al. (1997). Technologija avtomatizirovannogo proizuodstva, Minsk, DizainPRO, 1997, 216 s., ISBN 985-6182-16-6

[2] CYKLIS, J. (1985). Application of the Model for the Simulation of Discrete production Systems. ASME, 3, 1985, pp. 33-45

[3] EARLE, J. H, (2000). Graphycs Technology. New York Eddison -Wesley Publishong Company, New York, 2000, 380 pp.

[4] HAMMER, H. (1984). Verbesserung der Wirtschaftlichkeit durch flexible Automatisierung beim Bohren und Fräsen. Zeischrift Wirtschaftlichkeit Fertigung. VDI-Z, 127, 1984, Nr. 18.

[5] IVANOV, I.I.., VORONOV, S.A. (2018). Processing parameters influence on dynamics of vibratory drilling with adaptive control. In MATEC Web of Conferences vol. 226, p. EDP Sciences, 2018. 
[6] JERZAK, I e al. (2017). The integrity of the surface after milling of uenched bearing stell. Manufacturing Technology 2017, No.4, pp. 13-20.

[7] KALPAKJIAN, S. (2001). Manufacturing Engineering and Technology. Prentice Hall, New Yersey, 2001, 1148 pp.

[8] KOVAČ, P., MIKILIČ, D. (1998). Rezanje metala. Univerzitet v Novom Sadu, 1998, s., ISBN 86-899-40015-1

[9] KUNDRÁK, J. e al. (2019). Effect of Edge Geometry on Cutting Forces in Face Milling with Different Feed Rates. Manufacturing Technology, 2019, Vol. 19, No. 6, pp. 984-992

[10] KUNDRÁK, J. et al. (2018). Analysis of the effect of chip size ratio and cutting forces in face milling for various cutting speeds. Manufacturing Technology, 2018, Vol 18, No. 3, pp. 431438.
[11] LAMIT, L. G. (1999). Technical Drawing and Design. New York: West Publishing Company, 1999, 944 pp.

[12] TLUSTÝ, J. (1993). High Speed Machining. Annals of the CIRP, Vol. 42/1993, pp.56-59

[13] WECK, M. , et al. (1993). Offene NC Systeme, Grundlage Herstellerudabhängiger Flexibilität. VDI-Z 135, 1993

[14] WASILEWSKI, M. et al. (2019). A new efficient adaptive control of torsional vibrations induced by switched nonlinear disturbances. International Journal of Applied Mathematics and Computer Science. 2019 Jun 1, Vol.29, No.2, pp. 285303.

[15] YAMAZYKI, K. et al. (1990) Real-timeModel Reference Adaptive Control of 3-D Sculptured Surface Machining. Annals of the CIRP, Vol. 40/1990, pp. 479-482. 